\title{
Okul Öncesi Öğretmen Adaylarının Aile Katılımına Yönelik Tutumları ile Aile Katılımına Yönelik Bariyer Algıları Arasındaki İlişki
}

\author{
The Relationship Between Preschool Teacher Candidates' Attitudes Towards Family Participation and \\ Perceived Barriers about Parent Involvement
}

\author{
Özgül POLAT* (iD, Ebru AYDIN (D), Nevin AKARSU (iD
}

\begin{abstract}
ÖZ
Amaç: Bu araştırmada okul öncesi öğretmen adaylarının aile katılımına yönelik tutumları ile aile katılımına yönelik bariyer algıları arasındaki ilişkinin incelenmesi amaçlanmıştır. Bu amaç doğrultusunda şu sorulara cevap aranmıștır: (a) öğretmen adaylarının aile katılımına yönelik tutumları ve bariyer algıları demografik özelliklerine (anne-baba öğrenim durumu, lisans eğitimi sürecinde aile katılımına yönelik herhangi bir ders almış olma durumu, okul öncesi eğitim alma durumu) göre farklılık göstermekte midir?, (b) öğretmen adaylarının aile katılımına yönelik tutumları ile aile katılımına yönelik bariyer algıları arasında anlamlı bir ilişki var midır?

Yöntem ve Araçlar: Bu çalışma, ilişkisel tarama modelinde yürütülmüş betimsel bir çalışmadır. Araştırmada, okul öncesi öğretmen adaylarının aile katılımına yönelik tutumları ile aile katılımı bariyer algıları arasında birlikte bir değişimin var olup olmadığı incelenmektedir. Araştırmanın katılımcıları, olasılık dışı örnekleme yaklaşımlarından "uygun örnekleme" yöntemiyle belirlenen 284 okul öncesi öğretmen adayıdır. Çalışmada, Öğretmen Adayı Bilgi Formu, Aile Katılımına Yönelik Tutum Ölçeği ve Aile Katılımı Bariyer Algısı Formu kullanılmıştır.

Sonuçlar: Araştırma sonucunda; lisans eğitiminde aile katılımı dersi almış olan öğretmen adayları ile henüz aile katılımı dersi almamış olan öğretmen adaylarının aile katılımına yönelik tutumlarında ve aile katılımına yönelik bariyer algılarında anlamlı bir farklılık bulunmadığı, öğretmen adaylarının aile katılımına yönelik tutumları ve bariyer algılarının anne öğrenim düzeyine göre anlamlı bir farklılık göstermediği, baba öğrenim düzeyinin öğretmen adaylarının aile katılımına yönelik bariyer algılarında anlamlı bir farklılık oluşturmadığı ancak aile katılımına yönelik tutumlarda anlamlı bir farklılık oluşturduğu, okul öncesi eğitim almış olan öğretmen adaylarının aile katılımına yönelik tutumlarının okul öncesi eğitim almamış olan öğretmen adaylarından anlamlı olarak daha yüksek olduğu belirlenmiştir. Bunlarla birlikte, öğretmen adaylarının aile katılımına yönelik olumlu tutumları arttıkça, aile katılımına yönelik bariyer algılarının azaldığı, aile katılımına yönelik bariyer algıları arttıkça aile katılımına yönelik olumlu tutumlarının azaldığı sonucuna ulaşılmıştır.
\end{abstract}

Anahtar Kelimeler: Aile katılımı bariyer algısı, Aile katılımına yönelik tutum, Okul öncesi öğretmen adayları

\begin{abstract}
Purpose: The present study aimed to examine the relationship between pre-service pre-school teachers' attitudes towards family participation and their barrier perception towards the participation. More specially, this study attempted to answer the following questions: (a) Are pre-service teachers' attitudes towards family participation and barrier perceptions differ according to their demographic characteristics (parents' education status, having taken any lessons for family participation, receiving pre-school education)?, (b) Is there a significant relationship between pre-service teachers' attitudes towards family participation and their barrier perception towards family participation?

Method and Materials: This study is a descriptive research conducted in relational survey model. In the present study, the relationship pre-school pre-service teachers' attitudes towards family participation and family participation barrier perceptions was examined. 284 pre-service teachers attending the Preschool Teaching program participated in the study. In the study, the Personal Information Form, Attitude Scale Towards Family Participation, and the Family Participation Barrier Perception Form were used.

Results: According to the first finding obtained from the study, there is no significant difference in the attitudes towards family participation and barrier perceptions of family participation of pre-service teachers who have taken family participation course in undergraduate education and those who have not yet taken family participation course. Teacher candidates' attitudes towards family participation and barrier perceptions do not show a significant difference according to the education level of the mother. While the father's education level does not make a significant difference in the barrier perceptions of teacher candidates towards family participation, it does create a significant difference in attitudes towards family participation. According to another finding obtained from the study, the attitudes of teacher candidates who have received pre-school education towards family participation are significantly higher than those who have not received preschool education. As the second conclusion, as the positive attitude towards family participation increased, the barrier perception towards family participation decreased; similarly, as the barrier perception towards family participation increased, the positive attitude towards family participation decreased.
\end{abstract}

Keywords: Attitudes towards family participation, Perceived barriers about parent involvement, Preschool teacher candidate

* Marmara Üniversitesi Atatürk Eğitim Fakültesi Temel Eğitim Bölümü

Sorumlu Yazar/Correspondence Author: Özgül POLAT

E-posta/E-mail: polatozgul@gmail.com

Geliş Tarihi/Received: 16.02.2021

Kabul Tarihi/Accepted: 12.04 .2021

Ç. Yayınlanma Tarihi/Online Published: 31.05.2021 


\section{GİRIŞ}

Brofenbrenner (1979); çocuk, aile ve toplum arasındaki ilişkileri açılayabilmek için geliştirdiği "Ekolojik Sistem" kuramında çocukların gelişirken çevre, aile ve toplum ile sürekli etkileşim halinde olduğunu belirtmiştir. Bu kuram, çocukların gelişiminde birbirine bağlı olan beş sistemin (mikrosistem, mezosistem, egzosistem, makrosistem ve senkrosistem) sosyal ve kültürel çevredeki etkileşimlerini temel almaktadır. Aile, doğumdan itibaren çocuğun bakım, koruma, gelişim ve eğitiminden sorumlu ilk kurumdur. Aynı zamanda çocuğun ilk sosyal çevresi de olan aile, sergilediği tutumlarla çocuğun gelişimini olumlu ya da olumsuz etkileyebilmektedir (Garbarino ve Ganzel, 2000). Çocukların erken yaşta etkileşimde bulundukları diğer bir kurum ise okul öncesi eğitimdir. Ekolojik sistemler kuramına göre aile, okul ve toplum çocukların büyümesinde, öğrenim görmesinde ve gelişimsel ihtiyaçlarının karşılanmasında paylaşıma dayalı bir bağa sahiptir (Epstein, 2001). Bu nedenle, okul öncesi eğitim sürecinde ebeveyn, öğretmen ve okul etkileşiminin niteliği çocukların gelişimi ve eğitimi açısından son derece önem taşımaktadır.

Milli Eğitim Bakanlığı tarafından hazırlanan Okul Öncesi Eğitim Programında (2013a) ebeveyn ve öğretmen etkileşimini oluşturan aile katılım çalışmalarının önemi vurgulanarak öğretmenlere rehber olması için "Bütünleştirilmiş Aile Destek Eğitim Rehberi” hazırlanmıştır (MEB, 2013b). Bu çabalarla birlikte, aile katılımı etkinliklerinin uygulanması noktasında bir takım eksiklikler ve sorunlar olduğu söylenmektedir. Yapılan araştırmalarla okul öncesi dönemde gerek ailelerin gerekse öğretmenlerin çocukların gelişimi ve eğitimi için birlikte çalışmaya istekli oldukları, ancak bunu yeterince başaramadıkları, aile katılım çalışmalarının önünde birçok engel bulunduğu belirlenmiştir (Günay Bilaloğlu ve Aktaş Arnas, 2019; Güzelyurt, Bilge ve Ökten, 2019; Orçan Kaçan, Kimzan, Güler Yıldız ve Çağdaş, 2019; Toran ve Özgen, 2018).

Aile katılım çalışmalarının uygulanmasını engelleyen etmenler, "aile katılımına yönelik bariyer" olarak adlandırılmaktadır (Hornby, 2011). Bubariyerler, hem öğretmenler hem de ebeveynler tarafından geliştirilebilmektedir. Literatürde, bariyer algılarının neler olduğunu açıklamaya yönelik farklı yaklaşımlar bulunduğu görülmektedir. Genel olarak bu bariyerler; öğretmenlerin aile katılımı hakkında yeterli düzeyde eğitim almamış olması (Greenwood ve Hickman, 1991; Smith, 2008), ailelerin zaman, para ve çalışma durumundan kaynaklanan sinırlılıklara sahip olması (Greenwood ve Hickman, 1991; Hornby ve Lafaele, 2011; Smith, 2008; Keyser, 2006), ailelerin ve öğretmenlerin çocukların eğitimine yönelik farklı amaçlara sahip olmasıdır (Greenwood ve Hickman, 1991; Hornby ve Lafaele, 2011; Keyser, 2006). Bunlarla birlikte aileler ve öğretmenlerin aile katılımına yönelik bariyer algıları bir takım yanlış inançlardan da kaynaklanabilmektedir. Bunlardan bazıları; iyi bir öğretmenin öğrenci sorunlarını kendi başına çözebildiği yönünde yaygın bir kanı olması, öğretmenlerin bir çoğunun ebeveynlerin onları önemsemediğini ve desteklemediğini varsayması, aile katılımı çalışmaları için özel becerilerin gerekli olduğuna yönelik yanlış bir inanca sahip olunmasıdır (Canter ve Canter, 1991).

Literatürden yola çıkarak, aile katılımına yönelik bariyerlerin oluşmasında öğretmenlerin aile katılım çalışmalarına yönelik tutumlarının da oldukça etkili olduğu söylenebilmektedir (Davies, 1988; Mendez, 2010; Morris ve Taylor, 1998). Bariyerlerin oluşmasında öğretmenlerin önemli bir rolünün olmasına karşın bariyerlerin aşılmasında da en önemli role yine öğretmenlere düşmektedir (Savacool, 2011). Nitekim aile katılım çalışmalarına dahil olan ebeveynlerin okul, personel, öğretmen ve okulun sunduğu eğitim hakkında aile katılım çalışmalarına dahil olmayan ebeveynlere göre daha olumlu tutumlar geliştirdikleri bilinmektedir (Herman ve Yeh, 1980; Jones ve White, 2000).

Son yıllarda ülkemize ait literatürde okul öncesi öğretmenlerinin aile katılımı hakkındaki görüş, tutum ya da uygulamaları üzerine gerçekleştirilmiş çeşitli araştırmalar bulunmaktadır (Abbak, 2008; Bayraktar, Güven ve Temel, 2016; Güzelyurt, Birge ve Ökten, 2019; Özyürek, Şalc1, Mamiyev, Çekiç, Sağlam ve Nazlı, 2018; Toran ve Özgen, 2018; Ünüvar, 2010) ve öğretmen adaylarının (Bartan ve Aydemir Özalp, 2019; Dönmez ve Ramazan, 2017; Tümkaya ve Altunkaynak, 2020). Bunlara ek olarak, Demircan (2012) tarafından öğretmenlerin aile katılımına yönelik bariyer algıları incelenmiş; Alaçam (2015) tarafından ise okul öncesi öğretmen adaylarının özyeterlik inançlarının bariyer algıları ile ilişkisi araştırılmışıı. Ancak okul öncesi öğretmen adaylarının aile katılımına yönelik inançları ile aile katılımına yönelik bariyer algılarını birlikte inceleyen bir çalışmaya rastlanmamıştır.

Lisans eğitim süreci, öğretmenlerin aile katılımına yönelik bilgi, beceri ve yeterlikleri kazanmaya başladıkları dönem (Tichenor, 2010) olmanın yanısıra öğretmenlerin aile katılımına yönelik bariyer algılarının da oluşmaya başladığı dönem olduğu düşünülmektedir (Keyser, 2006). Literatürde öğretmen adaylarının okul, aile ve bunlar arasındaki etkileşimlere yönelik düşüncelerinin lisans eğitimi sürecinde oluşmaya başladığ 1 ve bu düşüncelerin gelecek uygulamaları etkilemekte olduğu belirtilmektedir (Ahioğlu-Lindberg, 2014; Katz ve Bauch, 1999; Zygmunt- 
Fillwalk, 2006). Bu nedenle öğretmen adaylarının aile katılımına yönelik geliştirdikleri bariyer algılarının tespit edilmesi ve öğretmenlik mesleğine başlamadan önce mevcut durumlarının iyileştirilmesi amacıyla çeşitli çalışmaların gerçekleştirilmesi önem taşımaktadır. Bu bilgilerden hareketle mevcut araştırmada okul öncesi öğretmen adaylarının aile katılımına yönelik tutumları ile aile katılımına yönelik bariyer algıları arasındaki ilişkinin incelenmesi amaçlanmış ve şu sorulara yanıt aranmıştır:

Öğretmen adaylarının aile katılımına yönelik tutumları ve bariyer algıları demografik özelliklerine (anne-baba öğrenim durumu, lisans eğitimi sürecinde aile katılımına yönelik herhangi bir ders almış olma durumu, okul öncesi eğitim alma durumu) göre farklılık göstermekte midir?

Öğretmen adaylarının aile katılımına yönelik tutumları ile aile katılımına yönelik bariyer algıları arasında anlamlı bir ilişki var mıdır?

\section{YÖNTEM}

\section{Araştırma Deseni}

Bu çalışma, ilişkisel tarama modelinde yürütülmüş betimsel bir araştırmadır. Bu tip araştırmalarında iki ya da daha fazla sayıdaki değişkenler arasında beraber bir değişimin varlığının ya da derecesinin belirlenmesi amaçlanmaktadır (Fraenkel ve Wallen, 2009; Karasar, 2007). Mevcut araştırmada okul öncesi öğretmen adaylarının aile katılımına yönelik tutumları ile aile katılımı bariyer algıları arasında birlikte bir değişimin var olup olmadığı incelenmektedir.

\section{Katılımcılar}

Araştırma evrenini, 2018-2019 eğitim öğretim yılında Türkiye’nin çeşitli illerindeki üniversitelerin Okul Öncesi Öğretmenliği programına devam etmekte olan üçüncü ve dördüncü sınıf öğrencileri oluşturmaktadır. Aile katılımı dersi almış olmanın öğretmen adaylarının aile katılımına yönelik tutumları ya da aile katılımına yönelik bariyer algıları üzerinde anlamlı bir etkiye sahip olup olmadığını belirlemek amacıyla aile katlımı dersini henüz almamış olan üçüncü sınıf öğrencileri ve aile katılımı dersini almış olan dördüncü sınıf öğrencileri tercih edilmiştir. Araştırmada katılımcı öğretmen adaylarının sınıf düzeylerine yönelik bir analizde bulunulmamış, yalnızca aile katılım dersi almış olma durumları analizlere dahil edilmiştir. Araştırmanın katılımcıları, olasılık dışı örnekleme yaklaşımlarından "uygun örnekleme" yöntemiyle belirlenen 284 okul öncesi öğretmen adayıdır. Uygun örnekleme yönteminde araştırmacılar, veri toplama sürecini kolay ulaşabilecekleri ve belli karakteristikleri taşıyan katılımcılar ile gerçekleştirmektedirler (Balc1, 2001). Mevcut araştırmada, Google Form üzerinden oluşturulan bir link aracılığıyla katılımcı öğretmenlere ulaşılmaya çalışılmıştır.

Tablo 1. Katılımcıların Demografik Bilgilerine Ait Frekans ve Yüzde Dağılımları

\begin{tabular}{llll} 
Özellikler & & f & $\%$ \\
\multirow{2}{*}{ Cinsiyet } & Kadın & 265 & 93.3 \\
& Erkek & 19 & 6.7 \\
\hline \multirow{2}{*}{ Anne öğrenim durumu } & İlkokul ve altı & 163 & 57.39 \\
& Ortaokul ve lise & 95 & 33.45 \\
\hline \multirow{2}{*}{ Baba öğrenim durumu } & Üniversite & 26 & 9.15 \\
\hline \multirow{2}{*}{ Aile katılım dersi almış olma durumu } & İlkokul ve altı & 90 & 31.6 \\
\hline \multirow{2}{*}{ Okul öncesi eğitim almış olma durumu } & Ortaokul ve lise & 136 & 47.88 \\
& Üniversite & 58 & 20.42 \\
\hline & Evet & 175 & 61.6 \\
& Hayır & 109 & 38.0 \\
\hline
\end{tabular}

\section{Veri Toplama Araçları}

Çalışmada, araştırmacıların oluşturduğu Öğretmen Adayı Bilgi Formu, Yavuz Güler (2014) tarafından geliştirilen Aile Katılımına Yönelik Tutum Ölçeği ile Epstein ve Salinas (1993) tarafından geliştirilip Demircan (2012) tarafından 
Türkçe’ye uyarlaması yapılan Okul Aile İşbirliği Öğretmen Anketi’nin Aile Katılımı Bariyer Algısı Formu kullanılmıştır.

Öğretmen Adayı Bilgi Formu: Bilgi formu; öğretmen adaylarının cinsiyeti, anne-babalarının öğrenim durumu, aile katılımı dersi alıp almama durumu, okul öncesi eğitim alıp almama durumu ve anne-babalarının aile katılım uygulamalarına katılıp katılmama durumu ile ilgili altı sorudan oluşmaktadır.

Aile Katılımına Yönelik Tutum Ölçeği (AKYTÖ): Yavuz Güler (2014) tarafından geliștirilmiş olan ölçek, öğretmen adaylarının ailelerle çalışmaya yönelik tutumlarını belirlemek amacıyla kullanılmaktadır. Ölçeğin "İşbirliğini Destekleyici Tutumlar" (15 madde) ve "İşbirliğini Engelleyici Tutumlar" (10 madde) olmak üzere iki alt boyutu bulunmaktadır. Toplam 25 maddelik, 5’li likert tipindeki bu ölçekten alınabilen en düşük puan 25, en yüksek puan ise 125 'tir. Ölçekten alınan puanın düşük olması aile katılımına yönelik tutumun olumsuz olduğunu ifade etmektedir; puanlar yükseldikçe aile katılımına yönelik tutum olumlu yönde artış göstermektedir. Ölçeğin İşbirliğini Destekleyici Tutumlar alt boyutu için Cronbach alfa iç tutarlılık katsayısı .91, İşbirliğini Engelleyici Tutumlar için ise .89 olarak bulunmuştur. Ölçeğin tamamına ait içtutarlık katsayısı ise .92'dir. Açımlayıcı faktör analizi sonuçlarına göre İşbirliğini Destekleyici Tutumlar alt boyutunun toplam varyasın 33.07'sini, İşbirliğini Engelleyici Tutumlar alt boyutunun ise 10.54'ünü karşıladığı görülmüştür. Ölçme aracındaki iki faktörün beraber açıkladıkları toplam varyans ise 43.62'dir.

Mevcut araştırma için gerçekleştirilen analiz sonuçlarında ölçeğin tamamına ait Cronbach alfa değerinin .72 olduğu belirlenmiştir. Açımlayıcı faktör analizi sonuçlarına göre İşbirliğini Destekleyici Tutumlar alt boyutunun toplam varyansın 59.35’ini, İşbirliğini Engelleyici Tutumların ise 9.23’ünü karşıladığı görülmüştür. Ölçme aracındaki iki faktörün birlikte açılladıkları toplam varyans ise 68.58 olarak hesaplanmıştır.

Aile Katılımı Öğretmen Anketi - Aile Katılımı Bariyer Algısı Formu (AKBAF): Aile Katılımı Öğretmen Anketi, Epstein ve Salinas (1993) tarafından öğretmenlerin aile katılımı konusundaki tutumlarını belirlemek amacıyla geliştirilmiştir. Ölçeğin orjinali 5'li likert tipinde 10 maddeden meydana gelmektedir ve tek faktörlü bir yapıya sahiptir. Ölçeğin Türkçeye uyarlaması Demircan (2012) tarafından gerçekleştirilmiş ve uygun olmayan bir madde çıkarılarak dokuz maddeye yer verilmiştir. Yapılan çalışmada Cronbach alfa değeri .74 olarak hesaplanmıştır.

Ölçeğin öğretmen adaylarına yönelik kullanılabilmesi amacıyla Alaçam (2015) tarafından gerçekleştirilen çalışmada, orijinal ölçekte bulunan maddeler yeniden gözden geçirilmiş ve öğretmen adaylarına uygun hale getirilmiştir. Örneğin, orijinal ölçekte bulunan "ebeveynlerin çoğu okulla ilgili etkinliklere katılmak istemiyor" maddesi, "okulla ilgili etkinliklere katılmak ebeveynlerin çoğu tarafından tercih edilmez" şeklinde değiştirilmiştir. Hem değiştirilmiş versiyon için hem de mevcut araştırmada yapılan güvenirlik analizleri sonucunda Cronbach alfa değerleri 70 olarak bulunmuştur.

\section{Verilerin Toplanması ve Analizi}

Verilerin toplanma sürecinde okul öncesi öğretmen adaylarına ulaşılabilirliğinin kolaylaştıılması için Google Form üzerinden bir link oluşturulmuştur. Google Form; her bir katılımcının ölçme araçlarını online olarak doldurmasına imkân sağlamakla birlikte katılımcılardan herhangi bir tanımlayıcı kişisel veri istememektedir. Link aracılığıla online olarak doldurulan formlarda katılımcıların her bir maddeyi doldurması, herhangi bir maddeyi boş bırakmaması gerekmektedir; aksi halde bir sonraki madde işaretlenememektedir. Bu gibi avantajları nedeniyle araştırmanın veri toplama sürecinin online olarak Google formlar aracıllğılyla yapılmasına karar verilmiştir. Veri toplama araçları olarak Öğretmen Adayı Bilgi Formu, Aile Katılımına Yönelik Tutum Ölçeği ve Aile Katılımı Öğretmen Anketi-Aile Katılımı Bariyer Algısı Formu oluşturulan link üzerine yüklenmiştir. Oluşturulan link, okul öncesi öğretmen adaylarına internet üzerinden iletilmiş ve veriler bu şekilde elde edilmiştir. Verilerin tamamı yaklaşık bir buçuk aylık süreçte toplanmıştır.

Analizlerde ilk olarak Aile Katılımına Yönelik Tutum Ölçeği (AKYTÖ) ve Aile Katılımı Bariyer Algısı Formundan (AKBAF) alınan toplam puanlara ait minimum-maksimum değerlerin, aritmetik ortalamanın, standart sapmanın, standart hatanın, basıklık-çarpıklık değerlerinin incelenebilmesi amacıyla betimsel analizler gerçekleştirilmiştir. Ardından araştırmada elde edilen verilerin AKYTÖ ve AKBAF toplam puanları bazındaki dağılımının normalliğini test etmek amacıyla Kolmogrov Smirnov analizi gerçekleştirilmiştir. Analiz sonuçlarına Tablo 2'de yer verilmiştir.

Tablo 2'de görüldüğü üzere, örneklem grubunu oluşturan öğretmen adaylarının AKYTÖ ve AKBAF toplam puanlarının normal dağılımdan anlamlı bir farklılık gösterip göstermediğini belirlemek amacıyla yapılan Kolmogorov Smirnov analizi sonucunda dağılımın normal dağılımdan farklılığı anlamlı bulunmuştur ( $\mathrm{p}<, 001)$.

AKYTÖ ve AKBAF toplam puanlarının araştırmada yer verilen demografik değişkenlere göre dağılımının 
normalliğini test etmek amacıyla yapılan Kolmogrov Smirnov analizi sonuçlarına Tablo 2'te yer verilmiştir.

Tablo 2. Demografik Değişkenler İçin Normallik Testi Sonuçları

\begin{tabular}{|c|c|c|c|c|c|c|c|}
\hline Puanlar & Değişken & Gruplar & $\mathbf{n}$ & 1 & $\beta 2$ & KS & $\mathbf{p}$ \\
\hline \multirow{10}{*}{ AKYTÖ } & \multirow{3}{*}{ Anne öğrenim durumu } & İlkokul ve altı & 163 & -.425 & -.219 & .137 & .000 \\
\hline & & Ortaokul ve lise & 95 & .521 & .749 & .094 & .039 \\
\hline & & Üniversite & 26 & .853 & .535 & .153 & .122 \\
\hline & \multirow{3}{*}{ Baba öğrenim durumu } & İlkokul ve altı & 90 & .420 & .739 & .112 & .000 \\
\hline & & Ortaokul ve lise & 136 & .319 & -.539 & .119 & .041 \\
\hline & & Üniversite & 58 & -.745 & .804 & .130 & .001 \\
\hline & \multirow{2}{*}{ Aile katılım dersi almış olma } & Evet & 175 & .334 & .249 & .117 & .000 \\
\hline & & Hayır & 109 & -.485 & .311 & .110 & .002 \\
\hline & \multirow{2}{*}{ Okul öncesi eğitim almış olma } & Evet & 121 & -.504 & .465 & .124 & .000 \\
\hline & & Hayır & 163 & .413 & .530 & .114 & .000 \\
\hline \multirow{10}{*}{ AKBAF } & \multirow{3}{*}{ Anne öğrenim durumu } & İlkokul ve altı & 163 & .849 & 2.054 & .109 & .000 \\
\hline & & Ortaokul ve lise & 95 & .638 & 1.459 & .096 & .029 \\
\hline & & Üniversite & 26 & -.569 & -.118 & .136 & .200 \\
\hline & \multirow{3}{*}{ Baba öğrenim durumu } & İlkokul ve altı & 90 & .585 & 1.887 & .091 & .064 \\
\hline & & Ortaokul ve lise & 136 & 1.113 & 2.410 & .118 & .000 \\
\hline & & Üniversite & 58 & -.118 & -.088 & .078 & .200 \\
\hline & \multirow{2}{*}{ Aile katılım dersi almış olma } & Evet & 175 & .600 & 1.372 & .089 & .002 \\
\hline & & Hayır & 109 & .824 & 2.090 & .109 & .003 \\
\hline & \multirow{2}{*}{ Okul öncesi eğitim almış olma } & Evet & 121 & .869 & 2.399 & .117 & .000 \\
\hline & & Hayır & 163 & .489 & .873 & .101 & .000 \\
\hline
\end{tabular}

Tablo 2'de görüldüğ̈̈ üzere, AKYTÖ toplam puanları anne öğrenim durumu değişkeninde yer alan gruplar içerisinde; ilkokul ve altı ile ortaokul ve lise gruplarında normal dağılım göstermezken ( $\mathrm{p}<.005)$, üniversite öğrenim durumuna sahip grup içerisinde normal dağılım göstermektedir ( $p>005)$. AKYTÖ toplam puanları babam öğrenim durumu, aile katılımı dersi almış olma durumu ve okul öncesi eğitim almış olma durumundaki tüm gruplar için normal dağılım göstermemektedir ( $\mathrm{p}<.005)$. AKBAF toplam puanları ise anne öğrenim durumu değişkeninde yer alan gruplar içerisinde; ilkokul ve altı ile ortaokul ve lise gruplarında normal dağılım göstermezken $(\mathrm{p}<.005)$, üniversite öğrenim durumuna sahip grup içerisinde normal dağılım göstermektedir ( $\mathrm{p}>.005)$. AKBAF toplam puanları baba öğrenim durumu değişkeninde yer alan gruplar içerisinde; ortaokul ve lise grubunda normal dağılım göstermezken ( $\mathrm{p}<.005)$, ilkokul ve altı ile üniversite gruplarında normal dağılım göstermektedir ( $\mathrm{p}>$.005). Son olarak, AKBAF toplam puanlarının aile katılımı dersi almış olma durumu ve okul öncesi eğitim almış olma durumundaki tüm gruplar için normal dağılım göstermediği saptanmıştır ( $\mathrm{p}<.005)$.

Araştırmada, AKYTÖ ve AKBAF toplam puanları için ve demografik değişkenlerde yer alan tüm gruplar için normallik varsayımlarının karşılanmaması nedeniyle veri analizinde parametrik olmayan fark ve ilişki testlerinden yararlanılmasına karar verilmiştir. Araştırmanın ilk sorusuna uygun olarak AKYTÖ ve AKBAF puanlarının demografik özelliklere göre farklılaşıp farklılaşmadığının belirlenmesi amacıyla Mann Whitney U ve Kruskal Wallis- $\mathrm{H}$ testleri uygulanmıştır. Araştırmanın ikinci sorusuna uygun olarak AKYTÖ ile AKBAF puanları arasındaki ilişkinin anlamlılığının belirlenmesi amacıyla Spearman kolerasyon analizi gerçekleştirilmiştir. Bulgular tablolar halinde sunulmuştur.

\section{BULGULAR}

Katılımcı öğretmen adaylarına uygulanan Aile Katılımına Yönelik Tutum Ölçeği (AKYTÖ) ve Aile Katılımı Bariyer Algısı Formundan (AKBAF) alınan toplam puanlara ait betimsel analizlere Tablo 3’te yer verilmiştir. 
Tablo 3. AKYTÖ ve AKBAF Toplam Puanlarına Ait Betimsel Analizler

\begin{tabular}{lcccccccc}
\multicolumn{1}{c}{ Puanlar } & $\mathbf{n}$ & Min & Max & $\overline{\boldsymbol{x}}$ & $\boldsymbol{s h}_{\overline{\boldsymbol{x}}}$ & ss & $\mathbf{y 1}$ & $\boldsymbol{\beta 2}$ \\
AKYTÖ & 284 & 31.00 & 125.00 & 76.82 & .748 & 12.61 & .017 & .219 \\
AKBAF & 284 & 11.00 & 44.00 & 23.70 & .310 & 5.22 & .683 & 1.709 \\
\hline
\end{tabular}

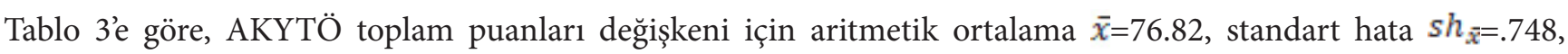
standart sapma $s s=12.61$, elde edilen en düşük puan $\min =31.00$, en yüksek puan maks=125.00, çarpıklık değeri $y 1=.017$, basıklık değeri $\beta 2=.219$ 'dur. AKBAF toplam puanları değişkeni için ise aritmetik ortalama $\bar{x}=23.70$, standart hata $=.310$, standart sapma $s s=5.22$, elde edilen en düşük puan $\min =11.00$, en yüksek puan maks=44.00, çarpıklık değeri $y 1=.683$, basıklık değeri $\beta 2=1.709$ olarak bulunmuştur.

Araştırmanın ilk sorusuna uygun olarak öğretmen adaylarının aile katılımına yönelik tutumlarının ve aile katılımına yönelik bariyer algılarının demografik özelliklerden aile katılımı dersi almış olma durumuna göre farklılık gösterip göstermediğini belirlemek amacıyla yapılan Mann Whitney U testi sonuçlarına Tablo 4’te yer verilmiştir.

Tablo 4. AKYTÖ ve AKBAF Toplam Puanlarının Aile Katılımı Dersi Almış Olma Durumuna Göre Farklılaşma Durumu için Mann Whitney U Testi Sonuçları

\begin{tabular}{|c|c|c|c|c|c|c|c|}
\hline Puan & Gruplar & $N$ & $\overline{\boldsymbol{x}}_{\text {sira }}$ & $\Sigma_{s i r a}$ & $U$ & $z$ & $p$ \\
\hline \multirow{3}{*}{ AKYTÖ } & Aile katılımı dersi alan & 175 & 140.36 & 24563.50 & \multirow{3}{*}{9163.50} & \multirow{3}{*}{-.556} & \multirow{3}{*}{.578} \\
\hline & Aile katılımı dersi almayan & 109 & 145.93 & 15906.50 & & & \\
\hline & Toplam & 284 & & & & & \\
\hline \multirow{3}{*}{ AKBAF } & Aile katılımı dersi alan & 175 & 146.80 & 256889.50 & \multirow{3}{*}{8785.50} & \multirow{3}{*}{-1.120} & \multirow{3}{*}{.263} \\
\hline & Aile katılımı dersi almayan & 109 & 135.60 & 14780.50 & & & \\
\hline & Toplam & 284 & & & & & \\
\hline
\end{tabular}

Tablo 4’te görüldüğü üzere, AKYTÖ puanlarına göre grupların aritmetik ortalamaları arasında aile katılımı dersi almış olma durumuna göre ( $\mathrm{z}=-.5561 ; \mathrm{p}>$.05) anlamlı bir farklılık bulunmamaktadır. Benzer şekilde, grupların AKBAF toplam puanlarına ait aritmetik ortalamaları arasında aile katılımı dersi almış olma durumuna göre $(\mathrm{z}=-1.120 ; \mathrm{p}>.05)$ anlamlı bir farklılık bulunmamaktadır.

Araştırmanın ilk sorusuna uygun olarak öğretmen adaylarının aile katılımına yönelik tutumlarının ve aile katılımına yönelik bariyer algılarının demografik özelliklerden anne-baba öğrenim durumuna göre farklılık gösterip göstermediğini belirlemek amacıyla yapılan Kruskal Wallis-H testi sonuçlarına Tablo 5'de yer verilmiştir.

Tablo 5. AKYTÖ ve AKBAF Toplam Puanlarının Anne-Baba Öğrenim Düzeyine Göre Farklılaşma Durumu için Kruskal Wallis-H Testi Sonuçları

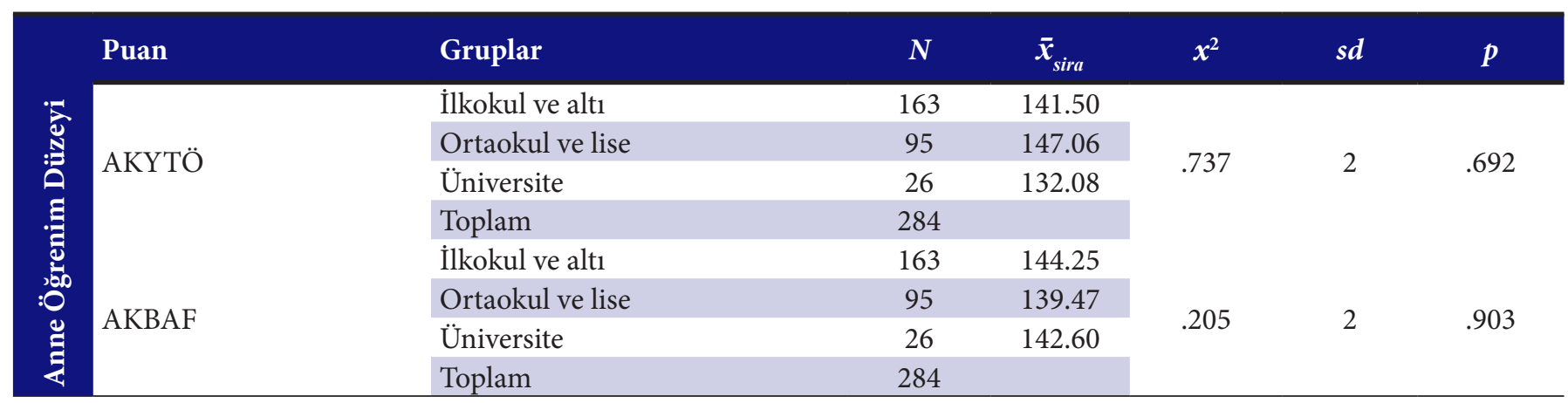




\begin{tabular}{|c|c|c|c|c|c|c|c|}
\hline \multirow{8}{*}{ 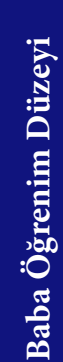 } & \multirow{3}{*}{ AKYTÖ } & İlkokul ve altı & 90 & 129.58 & \multirow{4}{*}{7.471} & \multirow{4}{*}{2} & \multirow{4}{*}{.024} \\
\hline & & Ortaokul ve lise & 136 & 145.92 & & & \\
\hline & & Üniversite & 58 & 159.81 & & & \\
\hline & \multirow{5}{*}{ AKBAF } & Toplam & 284 & & & & \\
\hline & & İlkokul ve altı & 90 & 132.52 & \multirow{4}{*}{2.397} & \multirow{4}{*}{2} & \multirow{4}{*}{.302} \\
\hline & & Ortaokul ve lise & 136 & 144.57 & & & \\
\hline & & Üniversite & 58 & 153.12 & & & \\
\hline & & Toplam & 284 & & & & \\
\hline
\end{tabular}

Tablo 5’de görüldüğü gibi, katılımcı öğretmen adaylarının AKYTÖ ölçeğinden aldıkları toplam puanlar anne öğrenim düzeyine göre anlamlı bir farklılık göstermemekte (x2=.737; p>.05); ancak baba öğrenim düzeyine göre anlamlı bir farklılık göstermektedir ( $\mathrm{x} 2=7.471 ; \mathrm{p}<.05)$. Katılımcı öğretmen adaylarının AKBAF ölçeğinden aldıkları toplam puanlar ise hem anne öğrenim düzeyi ( $\mathrm{x} 2=.205 ; \mathrm{p}>.05)$, hem de baba öğrenim düzeyi $(\mathrm{x} 2=2.397 ; \mathrm{p}>.05)$ açısından anlamlı bir farklılık oluşturmamaktadır.

$\mathrm{Bu}$ işlemin ardından, AKYTÖ toplam puanlarının baba öğrenim düzeyine göre oluşturduğu anlamlı farklılı̆̆ın hangi gruplardan kaynaklandığını belirlemek üzere tamamlayıcı karşılaştırma tekniklerine geçilmiştir. Bu amaçla kullanılan özel bir test tekniği bulunmadığından ikili karşılaştırmalarda tercih edilen Mann Whitney U uygulanmış ve elde edilen sonuçlar aşağıda sunulmuştur.

Tablo 6. AKYTÖ Toplam Puanlarının Baba Öğrenim Düzeyine Göre Farklılaşma Durumu için Mann Whitney-U Testi Sonuçları

\begin{tabular}{|c|c|c|c|c|c|c|c|}
\hline Puan & Gruplar & $N$ & $\overline{\boldsymbol{x}}_{\text {sira }}$ & $\Sigma_{\text {sira }}$ & $\boldsymbol{U}$ & $z$ & $p$ \\
\hline \multirow{6}{*}{ AKYTÖ } & İlkokul ve altı & 90 & 94.14 & 12803.50 & \multirow{2}{*}{3487.50} & \multirow{2}{*}{-1.276} & \multirow{2}{*}{.202} \\
\hline & Ortaokul ve lise & 136 & 105.37 & 6111.50 & & & \\
\hline & İlkokul ve altı & 90 & 103.94 & 14136.00 & \multirow{2}{*}{4820.00} & \multirow{2}{*}{-2.703} & \multirow{2}{*}{.007} \\
\hline & Üniversite & 58 & 127.94 & 11515.00 & & & \\
\hline & Ortaokul ve lise & 136 & 70.05 & 4063.00 & \multirow{2}{*}{2352.00} & \multirow{2}{*}{-1.014} & \multirow{2}{*}{.311} \\
\hline & Üniversite & 58 & 77.37 & 6963.00 & & & \\
\hline
\end{tabular}

Tablo 6’da görüldüğü üzere, AKYTÖ toplam puanlarının baba öğrenim düzeyine göre hangi gruplar arasında farklılaştığını belirlemek üzere yapılan Mann Whitney U testi sonucunda söz konusu farklılığın ilkokul ve altı öğrenim düzeyine sahip babalar ile üniversite öğrenim düzeyine sahip babalar arasında, üniversite öğrenim düzeyine sahip babalar lehine $\mathrm{p}<.05$ düzeyinde gerçekleştiği belirlenmiştir. Diğer grupların sıralamalar ortalamaları arasındaki farklılık istatistiksel olarak anlamlı bulunmamıştır ( $\mathrm{p}>.05)$. Tespit edilen bu farkın etki büyüklüğünün $\mathrm{r}=-0.22$ olduğu ve farkın küçük bir etkiye sahip olduğu belirlenmiştir.

Araştırmanın ilk sorusuna uygun olarak öğretmen adaylarının aile katılımına yönelik tutumlarının ve aile katılımına yönelik bariyer algılarının demografik özelliklerden okul öncesi eğitim almış olma göre farklılık gösterip göstermediğini belirlemek amacıyla yapılan Mann Whitney U testi sonuçlarına Tablo 7’de yer verilmiştir.

Tablo 7. AKYTÖ ve AKBAF Toplam Puanlarının Okul Öncesi Eğitim Almış Olma Durumuna Göre Farklılaşma Durumu için Mann Whitney U Testi Sonuçları

\begin{tabular}{|c|c|c|c|c|c|c|c|}
\hline Puan & Gruplar & $N$ & $\overline{\boldsymbol{x}}_{\text {sira }}$ & $\Sigma_{\text {sira }}$ & $\boldsymbol{U}$ & $z$ & $p$ \\
\hline \multirow{4}{*}{ AKYTÖ } & Okul öncesi eğitim alan & 121 & 157.05 & 19003.00 & \multirow{4}{*}{8101.00} & \multirow{4}{*}{-2.574} & \multirow{4}{*}{.010} \\
\hline & Okul öncesi eğitim almayan & 163 & 131.70 & 21467.00 & & & \\
\hline & Toplam & 284 & & & & & \\
\hline & Okul öncesi eğitim alan & 121 & 141.55 & 17127.50 & & & \\
\hline \multirow[t]{2}{*}{ AKBAF } & Okul öncesi eğitim almayan & 163 & 143.21 & 23342.50 & \multirow[t]{2}{*}{9746.50} & \multirow[t]{2}{*}{-.168} & \multirow[t]{2}{*}{.866} \\
\hline & Toplam & 284 & & & & & \\
\hline
\end{tabular}

Tablo 7’de görüldügü gibi, AKYTÖ puanlarına göre grupların aritmetik ortalamaları arasında okul öncesi eğitim almış olma durumuna göre $(\mathrm{z}=-2.574 ; \mathrm{p}<.05)$ anlamlı bir farklılık bulunmaktadır. Bununla birlikte, AKBAF toplam 
puanlarına ait aritmetik ortalamaları arasında okul öncesi eğitim almış olma durumuna göre ( $\mathrm{z}=-.168 ; \mathrm{p}>.05)$ anlamlı bir farklılık bulunmamaktadır. Tespit edilen bu farkın etki büyüklügünün $r=-0.152$ olduğu ve farkın küçük bir etkiye sahip olduğu söylenebilmektedir.

Araştırmanın ikinci sorusuna uygun olarak, AKYTÖ ve AKBAF puanları arasında anlamlı bir ilişki bulunup bulunmadığını belirlemek amacıyla Spearman kolerasyon analizi yapılmıştır. Analiz sonuçlarına Tablo 8'de yer verilmiştir.

Tablo 8. AKYTÖ ve AKBAF Toplam Puanları için Spearman Kolerasyon Analizi Sonuçları

\begin{tabular}{lccc} 
Değişkenler & $\mathbf{N}$ & $\mathbf{r}$ & $\mathbf{p}$ \\
AKYTÖ & 284 & -.127 & .032 \\
AKBAF & & -127 \\
\hline
\end{tabular}

Tablo 8’e göre, AKYTÖ ve AKBAF toplam puanları arasında negatif yönde düşük düzeyli (r=-.127) ve anlamlı $(\mathrm{p}<.05)$ bir ilişki olduğu saptanmıştır. Tabloda yer alan korelasyon katsayısına göre değişkenlerin birbirleri üzerinde açıkladıkları varyans \%01'dir.

\section{SONUÇ, TARTIŞMA VE ÖNERILER}

$\mathrm{Bu}$ araştırmada okul öncesi öğretmen adaylarının aile katılımına yönelik tutumları ile aile katılımına yönelik bariyer algıları çeşitli değişkenler açısından incelenmiş ve öğretmen adaylarının aile katılımına yönelik tutumları ile aile katılımına yönelik bariyer algıları arasındaki ilişki açıklanmaya çalışılmıştır. Araştırmadan elde edilen ilk bulguya göre, lisans eğitiminde aile katılımı dersi almış olan öğretmen adayları ile henüz aile katılımı dersi almamış olan öğretmen adaylarının aile katılımına yönelik tutumlarında ve aile katılımına yönelik bariyer algılarında anlamlı bir farklılık bulunmamaktadır. Literatürdeki bazı araştırmalarda, aile katılımı dersi almış öğretmen adaylarının aile katılımı etkinliklerini uygulama konusunda kendilerini daha hazır hissettikleri (Katz ve Bauch, 1999), aile katılımına yönelik özyeterlik inançlarının daha yüksek olduğu (Özen, 2018) ve daha olumlu görüşlere sahip oldukları (AhioğluLindberg, 2014; Uludağ, 2008) belirtilmektedir. Ekici (2016) ise aile katılımına yönelik tutumlarda aile katılımı dersi almış olan ve olmayan öğretmen adayları arasında anlamlı bir farklılık olmadığı sonucuna ulaşmıştır. Bununla birlikte, aile katılımı dersi alan ve almayan öğretmen adaylarının aile katılımına yönelik bariyer algılarını inceleyen herhangi bir araştırmaya rastlanmamıştır. Literatürdeki araştırma sonuçlarından ve mevcut araştırma sonucundan yola çıkarak aile katılımı dersi almış olmanın çeşitli yeterlikler ve görüşlerde farklılık oluşturduğu, ancak aile katılımına yönelik tutumlarda ve bariyer algılarında herhangi bir farklılık oluşturmadığı söylenebilmektedir.

Araştırmadan elde edilen bulgulara göre, öğretmen adaylarının aile katılımına yönelik tutumları ve bariyer algıları anne öğrenim düzeyine göre anlamlı bir farklılık göstermemektedir. Baba öğrenim düzeyi ise öğretmen adaylarının aile katılımına yönelik bariyer algılarında anlamlı bir farklılık oluşturmazken, aile katılımına yönelik tutumlarda anlamlı bir farklılık oluşturmaktadır. Bu farklılık, üniversite mezunu babalar lehine ilkokul ve altı öğrenim düzeyine sahip babalar arasında görülmektedir. Graue (2005), öğretmenlerin aile katılım çalışmalarında sergiledikleri tutumun; kendi yetiştikleri ortamdaki aile içi etkileşimlerden ve ebeveynlerin öğretim durumlarından etkilendiğini söylemektedir. Sosyal bilişsel öğrenme kuramına göre davranışları dönüştüren ana kaynaklardan biri deneyimlerdir (Bandura, 1977). Kendi ebeveynleri ile yakın ilişki ve açık iletişim kurabilmiş olan öğretmen adaylarının gelecekteki öğrencilerinin ebeveynleriyle olumlu ilişki kurabilme ve onları çocukların eğitimine dahil edebilme konusunda daha emin hissetmeleri beklenmektedir (Cheung ve Kam, 2019). Dolayısıyla, öğretmenlerin ve öğretmen adaylarının aile katılımına yönelik tutumlarının köken ailelerindeki sosyal ve eğitimsel ortamdan etkilendiğini söylemek mümkündür. Mevcut araştırma sonucunda sadece baba öğrenim düzeyinin aile katılımına yönelik tutumlarda farklılık oluşturduğu görülmektedir. $\mathrm{Bu}$ durumun, katılımcı grubun araştırmaya dahil edilmeyen özelliklerinden kaynaklanabileceği düşünülmektedir.

Araștırmadan elde edilen diğer bir bulguya göre, okul öncesi eğitim almıș olan öğretmen adaylarının aile katılımına yönelik tutumları okul öncesi eğitim almamıș olan öğretmen adaylarından anlamlı olarak daha yüksektir. Ancak, okul öncesi eğitim almış olma durumu aile katılımına yönelik bariyer algısında herhangi bir farklılık olușturmamaktadır. Yapılan araştırmalar bir çok tutum ve algının okul öncesi dönemde şekillenmeye başladığını göstermektedir (Aslan, 1992; Grodzinska, Jurzcak, Stepska, Nieszporek ve Bryda, 2006; Öztürk ve Yıkmış, 2013; Yavuzer, 1998). Bu nedenle, okul öncesi eğitim sürecindeki deneyimlerin aile katılımına yönelik olumlu tutumlar geliştirilmesine olanak sağladığı 
düşünülmektedir.

Araştırmadan elde edilen son bulguya göre; aile katılımına yönelik olumlu tutum arttıkça, aile katılımına yönelik bariyer algısının azaldığı, benzer şekilde aile katılımına yönelik bariyer algısı arttıkça da aile katılımına yönelik olumlu tutumun azaldığı ortaya çıkmıştır. İlgili literatürde yer alan çalışmalarda, aile katılımına yönelik olumsuz tutumun aile katılım çalışmalarına engel oluşturan durumlardan biri olduğu belirlenmiştir (Alaçam, 2015; Crites, 2008; Erdoğan ve Demirkasımoğlu, 2010; Flynn, 2007; Jeynes, 2016; Lindberg, 2017; Williams ve Sanchez, 2011). Buna ek olarak; birçok çalışmada öğretmenlerin sahip olduğu olumsuz tutum, okul-aile birlikteliğindeki engelleyici bir etmen olarak belirtilmiştir (Dor ve Rucker-Naidu, 2012; Horn, 2003; McAnuff-Gumbs, 2006). Dolayısıyla, mevcut araştırmadan elde edilen bulgunun literatüre paralellik gösterdiği söylenebilmektedir.

Öğretmenlerin aile katılımına karşı tutumlarının ve aile katılımının önündeki engellere yönelik algılarının ebeveynlerin etkinliklere katılım durumları üzerinde etkili olduğu bilinmektedir (Henderson ve Mapp, 2002; Koçyiğit, 2015; Pang ve Watkins, 2000; Westmoreland, Rosenberger, Lope ve Weiss, 2009). Nitelikli ve başarılı bir aile katılım çalışmasında öğretmenlerin merkezi bir rolü bulunmaktadır (Dauber ve Epstein, 1993; Tezel-Şahin ve Ünver, 2005). $\mathrm{Bu}$ nedenle, öğretmen yetiştirme programlarında yer alan aile katılım derslerinde yalnızca öğretmen-aile ilişkisine ve yapılabilecek uygulamalara değil; aynı zamanda katılım sürecinde ortaya çıkabilecek olası problemlere ve bu problemlere yönelik çözüm yollarına da yer verilmesi gerekmektedir (Mahmood, 2013). Bu bilgilerden yola çıkarak, lisans eğitim sürecinde öğretmen adaylarının aile katılım çalışmalarına yönelik olumlu tutumlar geliştirebilmesi ve bariyer algılarına yönelik bir müdahale oluşturulması açısından aile katılımı dersinin içeriğinin ve niteliğinin oldukça önem taşıdığı söylenebilmektedir.

Okul öncesi eğitim programlarının niteliğini arttıran önemli etmenlerden biri de öğretmenlerin, anne-babaların ve eğitim sürecinin diğer paydaşlarının işbirliğine dayalı çalışmalar yürütmesidir (Lino, 2014). Bu nedenle, öğretmen yetiştirme programlarında ilgili paydaşlarla ne şekilde çalışmalar yürütülebileceğine yer verilebilir. Lisans programlarında yer alan öğretmenlik uygulaması dersi kapsamında yapılan alan çalışmalarında öğretmen adaylarının aile katılımı etkinliklerini gözlemlemelerine ve uygulamalarına fırsat verilebilir.

\section{KAYNAKÇA}

Abbak, B. S. (2008). Okul öncesi eğitim programlarındaki aile katılımı etkinliklerinin anasınıfı öğretmenleri ve veli görüşleri açıcından incelenmesi. Yayımlanmamış yüksek lisans tezi, Çukurova Üniversitesi Sosyal Bilimler Enstitüsü, Adana.

Ahioğlu-Linberg, E.H. (2014). Final year faculty of education students' views concerning parent involvement. Educational Sciences: Theory ve Practice, 14(4), 1352-1361.

Alaçam, N. (2015). Parent involvement self-efficacy beliefs of pre-service early childhood teachers with respect to general selfefficacy beliefs and perceived barriers about parent involvement. Yayımlanmamış yüksek lisans tezi, Orta Doğu Teknik Üniversitesi Sosyal Bilimler Enstitüsü, Ankara.

Aslan, E. (1992). Benlik kavramı ve bireyin yaşamındaki etkileri. Marmara Üniversitesi Atatürk Eğitim Fakültesi Eğitim Bilimleri Dergisi, 4, 7-14.

Balcı, A. (2001). Sosyal bilimlerde araştırma yöntem, teknik ve ilkeler (3. baskı). Ankara: Pegem Yayıncılık.

Bandura, A. (1977). Self-efficacy: Toward a unifying theory of behavioral change. Psychological Review 84, 191-215.

Bartan, M., \& Aydemir Özalp, T. (2019). Okul öncesi öğretmen adaylarının etkinlik planlarında aile katılımı boyutunun incelenmesi. E-Kafkas Eğitim Araştırmaları Dergisi, 6(4), 21-30.

Bayraktar, V., Güven, G., \& Temel, Z.F. (2016). Okul öncesi kurumlarda görev yapan öğretmenlerin aile katılım çalışmalarına yönelik tutumlarının incelenmesi. Kastamonu Eğitim Dergisi, 24(2), 755-770.

Bronfenbrenner, U. (1979). The ecology of human development: Experiments by nature and design. Cambridge, MA: Harvard University Press.

Canter, L., \& Canter M. (1991). Parents on your side: A comprehensive parent involvement program for teachers. USA: Publication of Canter \& Associates Inc.

Cheung, S.K., \& Kam, C.S. (2019). Hong Kong pre-service early childhood teachers' attitudes towards parental involvement and the role of their family relationship quality. Journal of Education for Teaching, 45(4), 417-433.

Crites, C.V. (2008). Parent and community involvement: A case study. Yayımlanmamış doktora tezi, Liberty University, Lynchburg, VA. 
Darling, N. (2007). Ecological systems theory: The person in the center of the circles. Research in Human Development, 4(3-4), 203-217.

Dauber, S.L., \& Epstein, J.L. (1993). Parents' attitudes and practices of involvement in inner-city elementary and middle schools. N. F. Chavkin (Ed.). Families and schools in a pluralistic soceity içinde (ss. 53-71). Albany, NY: State University of New York.

Demircan, H.Ö. (2012). Developmentally appropriate practice and parental involvement in preschools: Parent and teacher perspectives. Yayımlanmamış doktora tezi, Orta Doğu Teknik Üniversitesi, Ankara.

Dor, A., \& Rucker-Naidu, T.B. (2012). Teacher attitudes toward parents' involvement in school: Comparing teachers in the USA and İsrael. Issues in Educational Research, 22(3), 246-262.

Dönmez, Ö., \& Ramazan, O. (2017). Okul öncesi öğretmen adaylarının aile katılımına yönelik tutumları ile öz-yeterlik inançları arasındaki ilişkinin incelenmesi. Yıldız Sosyal Bilimler Enstitüsü Dergisi, 1(1), 29-45.

Ekici, F.Y. (2013). Okul öncesi öğretmenliği lisans öğrencilerinin aile katılımına yönelik tutumlarının yaş, sınıf ve aile katılımıyla ilgili eğitim alıp almama durumlarına göre incelenmesi, Uluslararası Yükseköğretimde Yeni Eğilimler Kongresi: Değişime Ayak Uydurmak içinde (s.18-19). NTHE 2016, Nisan.

Epstein, J. L. (2001). School, family and community partnerships: Preparing educators and improving schools. Boulder, CO: Westwiew Press.

Epstein, J.L., \& Salinas, K.C. (1993). School and family partnerships: Surveys and Summaries. Baltimore, MD: Center on School, Family, and Community Partnerships, John Hopkins University.

Erdoğan, Ç., \& Demirkasımoğlu, N. (2010). Ailelerin eğitim sürecine katılımına ilişkin öğretmen ve yönetici görüşleri. Kuram ve Uygulamada Eğitim Yönetimi Dergisi, 16(3), 399-431.

Flynn, G. V. (2007). Increasing parental involvement in our schools: The need to overcome obstacles, promote critical behaviors, and provide teacher training. Journal of College Teaching \& Learning, 4(2), 23-30.

Fraenkel, Jack R., \& Wallen, Norman E. (2009). How to design and evaluate research in education (Seventh ed.). New York: McGraw-Hill.

Garbarino, J., \& Ganzel, B. (2000). The human ecology of early risk. J.P. Shonkoff \& S. J. Meisels. (Ed.). Handbook of early childhood intervention içinde. The USA: Cambridge University Press.

Graue, E., \& Brown, C.P. (2003). Preservice teachers' notions of families and schooling. Teaching and Teacher Education, 19, 719-735.

Graue, E. (2005). Theorizing and describing preservice teachers' images of families and schooling. Teachers College Record 107, 157-185.

Greenwood, G.E., \& Hickman, C.W. (1991). Research and practice in parent involvement: Implications for teacher education. The Elementary School Journal, 91(3), 279-288.

Grodzinska-Jurzcak, M., Stepska, A., Nieszporek, K., \& Bryda, G. (2006). Perception of environmental problems among preschool children in Poland. International Research in Geographical and Environmental Education, 15(1), 62-76.

Gu, W., \& Yawkey, T.D. (2010). Working with parents and family: Factors that influence chinese teachers' attitudes toward parent involvement. Journal of Instructional Psychology, 37(2), 146-152.

Günay Bilaloğlu, R., \& Aktaş Arnas, Y. (2019). Okul öncesi eğitimde aile katılımı engelleri ve süreçte karşılaşılan sorunlar. Hacettepe Üniversitesi Eğitim Fakültesi Dergisi, 34(3), 804-823.

Güzelyurt, T., Birge, F., \& Ökten, A. (2019). Okul öncesi öğretmenlerinin aile katılımına yönelik görüşleri. Kocaeli Üniversitesi Eğitim Dergisi, 2(1), 64-74.

Henderson, A.T., \& Mapp, K.L. (2002). A new wave of evidence: The impact of school, family, and community connections on student achievement. Austin: Southwest Educational Development Laboratory.

Herman, J.L., \& Yeh, J.P. (1980). Some effects of parental involvement in schools. Los Angeles, CA: University of California Center for the Study of Evaluation.

Horn, D. (2003). Preparing early childhood educators to work in diverse urban settings. Teachers College Record, 105(2), 226244.

Hornby, G. (2011). Parental involvement in childhood education: Building effective school-family partnership. New York: Springer.

Hornby, G. \& Lafaele, R. (2011). Barriers to parental involvement in education: An explanatory model. Educational Review, 63(1), 
37-52.

Jeynes, W. (2007). The relation of parental involvement to urban elementary secondary school student academic achievement. Urban Education, 42(1), 82-110.

Jeynes, W.H. (2016). Meta-analysis on the roles of fathers in parenting: are they unique? Marriage, Family Review, 52, $665-688$.

Jones, I., \& White, C.S. (2000). Family composition, parental involvement and young children's academic achievement. Early Child Development and Care, 161(1), 71-82.

Karasar, N. (2007). Bilimsel araştırma yöntemleri (17.baskı). Ankara: Nobel Yayıncılık.

Katz, L., \& Bauch, J.P. (1999). The peabody family involvement initiative: Preparing pre-service teachers for family/school collaboration. School Community Journal, 9(1), 185-204.

Keyser, J. (2006). From parents to partners. building a family-centered early childhood program. USA: Redleaf Press.

Koçyiğit, S. (2015). Family involvement in preschool education: Rationale, problems and solutions for the participants. Educational Sciences: Theory and Practice 15, 141-157.

Lindberg, E.N.,(2017). Aile katılımı: bir kavramsal ve durumsal analiz çalışması. Uluslararası Eğitim Bilimleri Dergisi, $13,51-72$.

Lino, D. (2014). Early childhood teacher education: How to enhance professional development. Journal Plus Education, 2, 200209.

Mahmood, S. (2013). First-year preschool and kindergarten teachers: Challenges of working with parents. School Community Journal, 23(2), 55-85.

McAnuff-Gumbs, M. (2006). Understanding teachers' attitudes toward barriers to family-school partnerships. Yayımlanmamış doktora tezi, Ohio University, Athens.

Mendez, J. L. (2010). How can parents get involved in preschool? Barriers and engagement in education by ethnic minority parents of children attending Head Start. Cultural Diversity and Ethnic Minority Psychology, 16(1), 26-36.

Milli Eğitim Bakanlığı (2013a). Okul öncesi eğitim programı. Ankara.

Milli Eğitim Bakanlığı (2013b). Okul öncesi eğitim programı ile bütünleştirilmiş aile destek eğitim rehberi (OBADER). Ankara.

Morris, V. G., \& Taylor, S. I. (1998). Alleviating barriers to family involvement in education: The role of teacher education. Teaching and Teacher Education, 14(2), 219-231.

Moseman, C.C. (2003). Primary teachers' beliefs about family competence to influence classroom practices. Early Education and Development, 14(2), 125-153.

Orçan Kaçan, M., Kimzan, İ., Güler Yıldız, T., \& Çağdaş, A. (2019). Öğretmen ve ebeveynlerin aile katılımını etkileyen etmenlere yönelik görüşlerinin incelenmesi. Eğitim Kuram ve Uygulama Araştırmaları Dergisi, 5(3), 370-381.

Özen, F. (2018). Okul öncesi öğretmenleri aile katılım çalışmalarına yönelik öz-yeterlik inançlarının incelenmesi. Yayımlanmamış yüksek lisans tezi, Pamukkale Üniversitesi, Eğitim Bilimleri Enstitüsü, Denizli.

Öztürk, T., \& Yıkmış, A. (2013). Ana sınıflarına devam eden normal çocukları bilgilendirmenin zihin engelli yaşıtlarına yönelik tutumlarına etkisi. Abant İzzet Baysal Üniversitesi Eğitim Fakültesi Dergisi, 13(1), 1-21.

Özyürek, A., Şalcı, O., Mamiyev, D., Çekiç, İ., Sağlam, C., \& Nazlı, B. (2018). Okul öncesi eğitimde baba katılımının öğretmen görüşlerine göre değerlendirilmesi. Uludağ Üniversitesi Eğitim Fakültesi Dergisi, 31(2), 613-631.

Pang, I.W., \& Watkins, D. (2000). Towards a psychological model of teacher-parent communication in Hong Kong primary schools. Educational Studies 26, 141-163.

Pedro, J.Y., Miller, R., \& Bray, P. (2012). Teacher knowledge and dispositions towards parents and families: Rethinking influences and education of early childhood pre-service teachers. Forum On Public Policy Online, 1, 1-15.

Savacool, J.L. (2011). Barriers to Parental Involvement in the Pre-Kindergarten Classroom. https://eric.ed.gov/?id=ED519173 adresinden erişildi.

Smith, T.C. (2008). An examination of the parental involvement factor on reading achivement scores in an inner city school. Yayımlanmamıs doktora tezi, Capella University, Minnesota.

Tezel-Şahin, F., \& Ünver, N. (2005). Okul öncesi eğitim programlarına aile katılımı. Kastamonu Eğitim Dergisi, 13(1), 23-31.

Tichenor, M.S. (2010). Pre-service teachers' attitudes toward parent involvement: Implications for teacher education. The Teacher Educator, 33(4), 248-259.

Toran, M., \& Özgen, Z. (2018). Okul öncesinde aile katılımı: Öğretmenler ne düşünüyor, ne yapıyor? Eğitimde Nitel Araştırmalar 
Dergisi, 6(3), 229-245.

Tümkaya, S., \& Altunkaynak, M. (2020). Öğretmen adaylarının aile katılımının etkililiği ve aile katılımına yönelik engelleri ile öğretmenliğe ilişkin tutum ve mesleki öz-yeterliklerinin ilişkisi. OPUS Uluslararası Toplum Araştırmaları Dergisi, 15(21), 604-632.

Uludağ, A. (2008). Elementary pre-service teachers' opinions about parental involvement in elementary children's education. Teaching and Teacher Education, 24, 807-817.

Ünüvar, P. (2010). Aile katılımı çalışmalarına yönelik ebeveyn ve öğretmen görüşlerinin karşılaştırılması. Kastamonu Eğitim Dergisi, 18(3), 719-730.

Westmoreland, H., Rosenberg, H.M., Lopez, M.E., \& Weiss, H. (2009). Seeing is believing: Promising practices for how school districts promote family engagement. Harvard: Family Research Project.

Williams, T., \& Sanchez, T. (2011). Identifying and decreasing barriers to parent involvement for inner-city parents. Youth \& Society, 45(1), 54-74.

Yavuz Güler, Ç. (2014). Öğretmen adayları için Aile Katılımına Yönelik Tutum Ölçeğinin geliştirilmesi: Geçerlik ve güvenirlik çalışması. Bartın Üniversitesi Eğitim Fakültesi Dergisi, 3(2), 213-232.

Yavuzer, H. (1998). Çocuk eğitimi el kitabı. İstanbul. Remzi Kitabevi.

Zygmunt-Fillwalk, E.M. (2006). The difference a course can make: Pre-service teachers' perceptions of efficacy in working with families. Journal of Early Childhood Teacher Education, 27(4), 327-342. 


\title{
The Relationship Between Preschool Teacher Candidates' Attitudes Towards Family Participation and Perceived Barriers about Parent Involvement
}

\author{
Özgül POLAT (D), Ebru AYDIN (iD, Nevin AKARSU
}

\section{Introduction and purpose}

The quality of parent and teacher interaction during pre-school years is extremely important. Both parents and teachers are willing to work together for the development and education of children in the preschool period, but they cannot achieve this, and there are many obstacles to family participation activities (Günay Bilaloğlu ve Aktaş Arnas, 2019; Güzelyurt, Bilge ve Ökten, 2019; Orçan Kaçan, Kimzan, Güler Yıldız ve Çağdaş, 2019; Toran ve Özgen, 2018). Factors that hinder the implementation of family participation studies are called barriers to family participation (Hornby, 2011). Based on the literature, it can be said that teachers' attitudes towards family participation studies are very effective in forming barriers to family participation (Davies, 1988; Mendez, 2010; Morris ve Taylor, 1998). In recent years, there are various studies conducted on the opinions, attitudes or practices about family participation of preschool teachers (Abbak, 2008; Bayraktar, Güven \& Temel, 2016; Güzelyurt, Birge \& Ökten, 2019; Özyürek, Şalc1, Mamiyev, Çekiç, Sağlam and Nazlı, 2018; Toran \& Özgen, 2018; Ünüvar, 2010), and pre-service teachers (Bartan \& Aydemir Özalp, 2019; Dönmez \& Ramazan, 2017; Tümkaya \& Altunkaynak, 2020). In addition, Demircan (2012) examined teachers' perceptions of barrier to family participation, but there was no study examining pre-service teachers' perceptions of barriers towards family participation. Based on this information, the present study aimed to examine the relationship between pre-service pre-school teachers' attitudes towards family participation and their barrier perception towards the participation. More specially, this study attempted to answer the following questions:

1. Are pre-service teachers' attitudes towards family participation and barrier perceptions differ according to their demographic characteristics (parents' education status, having taken any lessons for family participation, receiving pre-school education)?

2. Is there a significant relationship between pre-service teachers' attitudes towards family participation and their barrier perception towards family participation?

\section{Methodology}

This study is a descriptive research conducted in relational survey model. In relational survey studies, it is aimed to determine the presence or degree of a change between two or more variables (Fraenkel \& Wallen, 2009; Karasar, 2007). In the present study, the relationship pre-school pre-service teachers' attitudes towards family participation and family participation barrier perceptions was examined.

284 pre-service teachers attending the Preschool Teaching program participated in the study. In order to determine whether taking family participation course had a significant effect on teacher candidates' attitudes towards family participation or their barrier perceptions towards family participation, third-year students who had not yet taken the family participation course and fourth-year students who had taken the family participation course were preferred.

In the study, the Personal Information Form developed by the researchers, the Attitude Scale towards Family Participation developed by Yavuz Güler (2014) and the Family Participation Barrier Perception Form of the SchoolFamily Cooperation Teacher Questionnaire developed by Epstein and Salinas (1993) and adapted into Turkish by 
Demircan (2012) were used.

During the data collection process, a link was created via Google Form in order to facilitate accessibility to preservice preschool teachers. As data collection tools, Personal Information Form, Attitude Scale towards Family Participation and Family Participation Teacher Questionnaire-Family Participation Barrier Perception Form were uploaded on the link. The link was transmitted to pre-school pre-service teachers' over the internet and the data was obtained in this way. It takes approximately five to 10 minutes to complete each form. All of the data were collected in about a month and a half.

The data obtained in the research were analyzed through the SPSS 21 package program. In the analyzes, descriptive analysis of the total scores obtained from the Attitude Scale towards Family Participation Scale and the Perception of Family Participation Barrier Form were performed. In accordance with the first question of the study, Mann Whitney $\mathrm{U}$ and Kruskal Wallis- $\mathrm{H}$ test were applied in order to determine whether the scores differ from demographic characteristics. In accordance with the second question of the study, Spearman correlation analysis was conducted to determine the significance of the relationship between the scores.

\section{Results, conclusion and suggestions}

According to the first finding obtained from the study, there is no significant difference in the attitudes towards family participation and barrier perceptions of family participation of pre-service teachers who have taken family participation course in undergraduate education and those who have not yet taken family participation course. Teacher candidates' attitudes towards family participation and barrier perceptions do not show a significant difference according to the education level of the mother. While the father's education level does not make a significant difference in the barrier perceptions of teacher candidates towards family participation, it does create a significant difference in attitudes towards family participation. This difference is seen in favor of fathers who are university graduates, among fathers with primary school and below education. According to another finding obtained from the study, the attitudes of teacher candidates who have received pre-school education towards family participation are significantly higher than those who have not received pre-school education. However, having received pre-school education has no effect on the barrier perception towards family participation. According to the second finding obtained from the research, as the positive attitude towards family participation increased, the barrier perception towards family participation decreased; similarly, as the barrier perception towards family participation increased, the positive attitude towards family participation decreased. The results obtained from the research have been discussed based on the relevant literature. 